\title{
BMJ Open Measuring 21 low-value hospital procedures: claims analysis of Australian private health insurance data (2010-2014)
}

\author{
Kelsey Chalmers, ${ }^{1,2}$ Sallie-Anne Pearson, ${ }^{3}$ Tim Badgery-Parker, ${ }^{1,2}$ Jonathan Brett, ${ }^{3}$ \\ Ian A Scott, ${ }^{4,5}$ Adam G Elshaug ${ }^{1}$
}

To cite: Chalmers $\mathrm{K}$, Pearson S-A, Badgery-Parker T, et al. Measuring 21 lowvalue hospital procedures: claims analysis of Australian private health insurance data (2010-2014). BMJ Open 2019;9:e024142. doi:10.1136/ bmjopen-2018-024142

\section{- Prepublication history and} additional material for this paper are available online. To view these files, please visit the journal online (http://dx.doi. org/10.1136/bmjopen-2018024142).

Received 12 May 2018 Revised 19 November 2018 Accepted 27 November 2018

Check for updates

(C) Author(s) (or their employer(s)) 2019. Re-use permitted under CC BY-NC. No commercial re-use. See rights and permissions. Published by BMJ.

For numbered affiliations see end of article.

Correspondence to Professor Adam G Elshaug; elshaug@sydney.edu.au

\section{ABSTRACT}

Objective To examine the prevalence, costs and trends (2010-2014) for 21 low-value inpatient procedures in a privately insured Australian patient cohort.

Design We developed indicators for 21 low-value procedures from evidence-based lists such as Choosing Wisely, and applied them to a claims data set of hospital admissions. We used narrow and broad indicators where multiple low-value procedure definitions exist.

Setting and participants A cohort of 376354 patients who claimed for an inpatient service from any of 13 insurance funds in calendar years 2010-2014; approximately $7 \%$ of the privately insured Australian population.

Main outcome measures Counts and proportions of low-value procedures in 2014, and relative change between 2010 and 2014. We also report both the Medicare (Australian government) and the private insurance financial contributions to these low-value admissions.

Results Of the 14662 patients with admissions for at least 1 of the 21 procedures in $2014,20.8 \%-32.0 \%$ were low-value using the narrow and broad indicators, respectively. Of the 21 procedures, admissions for knee arthroscopy were highest in both the volume and the proportion that were low-value (1607-2956; $44.4 \%-81.7 \%$ ). Seven low-value procedures decreased in use between 2010 and 2014, while admissions for low-value percutaneous coronary interventions and inpatient intravitreal injections increased (51\% and $8 \%$, respectively). For this sample, we estimated 2014 Medicare contributions for admissions with low-value procedures to be between $\$ A 1.8$ and $\$ A 2.9$ million, and total charges between $\$ A 12.4$ and $\$ A 22.7$ million.

Conclusions The Australian federal government is currently reviewing low-value healthcare covered by Medicare and private health insurers. Estimates from this study can provide crucial baseline data and inform design and assessment of policy strategies within the Australian private healthcare sector aimed at curtailing the high volume and/or proportions of low-value procedures.

\section{INTRODUCTION}

Low-value healthcare, or interventions that confer little or no benefit on patients while incurring avoidable cost, ${ }^{1}$ is primarily a
Strengths and limitations of this study

- We directly measured the prevalence and changes over time of 21 low-value procedures in a private health insurance claims data set.

- We labelled low-value procedures based on published, clinical recommendations relevant to and observable in this data set.

- We used broad and narrow indicators to estimate an interval of these low-value procedures to account for the trade-off between the sensitivity and specificity of the indicators in claims data.

- Our investigation of low-value care is limited to inpatient care reimbursed by a subset of Australian private health insurers.

- While these indicators provide baseline results for a broad range of procedures, these indicators have yet to be validated against other data sources.

patient safety concern with economic implications. Campaigns such as Choosing Wisely (CW) are drawing attention to low-value care. ${ }^{2}$ Despite this, only cursory insights into the scale of the problem are available, and most measurement research to date has focused on the extent of low-value care in routine practice within the USA. ${ }^{3}$ Understanding the scale of the problem in other countries, including Australia, and identifying which low-value services are most problematic are necessary in formulating actionable remedies. This requires baseline estimates of low-value service use across different healthcare settings.

This study focusses on low-value procedures provided during hospital admissions that are partially funded through private health insurance. While Australia has a government-funded healthcare system providing universal access to procedures in state-run public hospitals, Australians can choose (and are incentivised) to purchase supplementary 'private health insurance', which covers care 
provided by private practitioners during admissions in both private and public hospitals. In June 2014, $47 \%$ of Australians were members of a private health fund with hospital coverage. ${ }^{4}$ Private health insurance funded $57 \%$ of elective procedure admissions occurring in all public or private hospitals, which were also partly funded by Medicare (the federal government's rebate system for medical services provided to private patients). ${ }^{5}$ The rates of low-value services provided within this large sector of the Australian healthcare system are unknown.

We directly measured low-value inpatient procedures provided within this private healthcare setting by applying definitions of low-value care developed from professionally led campaigns including CW. We adapted a method first developed in the US context ${ }^{6}$ and report the proportions of patients with admissions where they received these low-value procedures, along with the estimated costs of these procedures and changes in use over time.

\section{METHODS}

\section{Study population and data sources}

Hospital and Medical Benefits System (HAMBS) supplied the claims and Hospital Casemix Protocol data ${ }^{7}$ on 376 354 patients with at least one hospital admission funded by 1 of 13 health insurance funds during full calendar years $2010-2014$. This cohort was $54.7 \%$ female, and the mean $( \pm \mathrm{SD})$ age was $47.5( \pm 21.6)$ years. This sample represents approximately $7 \%$ of the privately insured Australian population with an inpatient admission during the 5-year study period. ${ }^{4}$ In 2014, there were 141244 patients in this cohort with hospital admissions across all Australian states and territories.

The data set uses Australian Classification of Health Interventions ${ }^{8}$ (ACHI) and/or the Medical Benefits Schedule $^{9}$ (MBS) item numbers to detail procedures performed during an admission, and the International Classification of Diseases Australian Modification 10th edition (ICD-10-AM) ${ }^{10}$ to classify primary and secondary diagnoses. The claims data also details the charges to the insurance fund from the hospital and medical providers, as well as the Australian federal government's contribution towards the medical costs of the admission (charges for privately admitted patients via Medicare), which is claimed using the recorded MBS item numbers.

\section{Patient involvement}

Patients were not directly involved in this project. However, patient and other groups have been heavily involved in various international CW campaigns, the recommendations from which are an important input to this study.

\section{Indicators of low-value procedures}

We based our low-value indicators on recommendations from the Royal Australasian College of Physicians EVOLVE campaign, ${ }^{11}$ the Australian CW campaign, ${ }^{2}$ CW campaigns from the USA, Canada, the UK, ${ }^{12-14}$ the National Institute of Health and Care Excellence do-not-do recommendations ${ }^{15}$ and an existing Australian low-value services list. ${ }^{16}$ The selection of recommendations is described in an associated methods paper. ${ }^{17}$ In brief, we selected recommendations from these sources if a) the procedures were eligible to be claimed to an Australian health insurance fund and b) the description of low-value procedure use was definable using the procedure and diagnosis codes routinely recorded within the claims data. These constraints precluded a large number of recommendations from our study, which is a common limitation when using direct measures in routinely collected data. ${ }^{18}$

We translated these recommendations into indicators of low-value procedures (see online supplementary table 1) based on (1) patients who received the procedure and (2) patients for whom the procedure would be likely to be low-value on the basis of their listed characteristics and clinical indication. As described by Schwartz et $a l^{6}{ }^{6}$ low-value service indicators have a sensitivity-specificity trade-off depending on the information in the data set, the interpretation of the low-value service recommendation/s and different recommendations relating to the same service. In cases where this trade-off existed, we applied a broad indicator to capture all potential instances of low-value procedures (ie, high sensitivity) and a narrow indicator to identify more certain instances of low-value procedures (ie, high specificity).

For example, a vaginal or laparoscopic hysterectomy is usually preferable to an abdominal hysterectomy, the latter deemed a low-value procedure. ${ }^{16}$ The broad indicator for this low-value procedure was whenever a patient received an abdominal hysterectomy and had no record of a concurrent caesarean section or history of pelvic malignancy, where the abdominal approach may be justified. The narrow (more stringent) indicator also excluded patients with a record of either pelvic peritoneal adhesions or endometriosis.

Two investigators (KC, TB-P) selected relevant MBS, ACHI or ICD-10-AM codes for the indicators, with clinical input from two others (JB, IS). We used diagnosis codes recorded during the admission in which the procedure occurred, or during previously funded admissions (within 12 months of the admission). A more detailed description of how indicators were developed on the basis of expert clinician review can be found in our associated methods paper. $^{17}$

\section{Analysis}

Following the framework on the direct measurement of low-value care described by Chalmers et al, ${ }^{19}$ here we report the 'service-centric' proportions of care (a measure of how many funded services were low-value) for all 21 procedures. Chalmers et $a l^{19}$ also describe an alternative reporting perspective, the 'patient-indication' proportion, representing the proportion of patients with the low-value indication and potentially able to receive the procedure who actually received it. However, the 
denominator in this equation was not ascertainable for most of the 21 procedures, as not all potential patients would be admitted and recorded within this data set. As a secondary analysis presented in online appendix 1, we report the patient-indication proportions for the four investigated procedures where this was possible.

\section{Relative change in procedure use}

We compared the proportion of low-value procedures in calendar year 2010 with that in 2014, with two exceptions: we reported changes in inpatient intravitreal injections from its introduction as an MBS item (and therefore approved for private health insurance funding) in 20122014; and percutaneous coronary interventions from 2011 to 2014 as this indicator required a longer period of look back for diagnoses and indications-more than 12 months before the procedure was undertaken-to determine if it was associated with a low-value indication. ${ }^{6} \mathrm{We}$ used a Poisson general linear model for the number of patients with a low-value procedure, offset by the log of all patients with an admission in that year. We repeated this for the number of patients with the procedure (low-value or not) as a comparator. The $95 \%$ CIs for the estimated change in proportions came from 1000 random samples with replacement (bootstrap samples) of the observed data.

\section{Costs of low-value procedure use}

We reported total cost estimates for low-value procedures (for both broad and narrow indicators) where more than five patients had the low-value procedure in 2014, and where the procedure was the primary reason for the admission. Costs were estimated based on average admission charges (including charges from the hospital and medical providers, as well as prosthesis charges) to HAMBS funds and, separately, the Medicare benefit (the contribution from the Australian government) for admissions in facilities where the respective procedure was the primary procedure. These average admission charges for each year were supplied by the Australian Health Service Alliance, and we used these as a standardised charge for those admissions associated with a low-value procedure.

We used RStudio for all analyses. ${ }^{20}$

\section{RESULTS}

\section{Extent of low-value procedures in 2014}

In 2014, 14662 (10.4\%) of all 141244 unique patients with a hospital admission received at least one of the 21 procedures. Of these 14662 patients, between 3044 (20.8\%) and $4695(32.0 \%)$ received a low-value procedure based on the narrow and broad indicators respectively (table 1 and figure 1). This equated to between $2.2 \%$ and $3.3 \%$ of all admitted patients (for any procedure) receiving a low-value procedure.

Knee arthroscopy revealed both high volumes and high proportions of low-value use (3620 patients; $44.4 \%-81.7 \%$ for narrow and broad indicators, respectively). Other high volume and proportional low-value use include abdominal hysterectomy (30.9\%-79.9\% of 298 patients), adenoidectomy performed during a tube insertion procedure (28.4\% of 303 patients, based on one recommendation ${ }^{15}$ with only one indicator), spinal fusion for low back pain $(1.5 \%-22.8 \%$ of 544 patients) and percutaneous coronary intervention (PCI) for patients with stable coronary disease $(12.5 \%-12.7 \%$ of 881 patients). Use and low-value proportion of inpatient intravitreal injections was also high, with 427 (96.8\%) of 441 patients in 2014 having an indication for which the procedure could have been safely conducted in an outpatient rather than inpatient setting.

Approximately $10 \%$ of endoscopies received by patients younger than 55 years were low-value (501 of 5021 patients), while $3.3 \%$ of colonoscopies for patients younger than 50 years were deemed low-value with a diagnosis of constipation (133 of 4017 patients).

\section{Temporal trends in low-value procedures}

Figure 2 shows the relative change between 2010 and 2014 for low-value procedures with non-negligible counts ( $\geq 5$ in 2014). There were decreases in both the overall volume of admissions, and for the proportion that were low-value, for knee arthroscopy, abdominal hysterectomy, endoscopy, colonoscopy, nasolacrimal duct procedures in patients 1 year or younger, and endovascular abdominal aneurysm repair or carotid endarterectomy for asymptomatic, high-risk patients.

One low-value procedure with a substantial increase in those with a low-value indication was PCI. Despite a $13 \%$ decrease in admissions for patients with a PCI, those with a low-value indication increased by $50 \%$ between 2011 and 2014. Admissions for inpatient intravitreal injections (as opposed to an outpatient setting) also increased by $8 \%$ following introduction of the related MBS item and therefore health insurance coverage in 2012. ${ }^{21}$

\section{Costs of low-value procedures}

We estimated costs for 13 low-value procedures without negligible counts in 2014 and were the principal reason for an admission. Total hospital, medical and prostheses charges using narrow and broad low-value indicators were between $\$ A 12.4$ and $\$ A 22.7$ million, respectively (table 2). Between 2010 and 2014, the total charges were estimated at \$A47.4-\$A86.9 million. The Medicare contribution towards the costs of these admissions was estimated at \$A1.78-\$A2.94 million in 2014, and \$A7.5-\$A12.4 million over the 5-year period.

\section{DISCUSSION}

To our knowledge, this is the first large-scale Australian study which directly measures low-value care within a private health insurance setting, and builds on similar international work. ${ }^{62-24}$ We could measure 21 in-hospital procedures, and estimated between $20.8 \%$ and $32.0 \%$ of patients undergoing at least one of these procedures 
Table 1 Low-value (LV) counts and percentage of patients with the LV procedure out of all patients with the procedure, for 21 hospital procedures

\section{4}

\section{Patients with procedure}

(n)

Knee arthroscopy

$(n=3620)$

Endoscopy; age $<55$ years

$(\mathrm{n}=5021)$

\begin{tabular}{|c|c|c|c|c|}
\hline $\begin{array}{l}\text { Intravitreal injections } \\
(\mathrm{n}=441)\end{array}$ & No indication requiring inpatient care & 427 & 96.8 & 8.2 (3.8 to 11.6$)$ \\
\hline \multirow{2}{*}{$\begin{array}{l}\text { Abdominal hysterectomy } \\
(\mathrm{n}=298)\end{array}$} & Broad: benign disease & 238 & 79.9 & $-26.5(-37.0$ to -17.0$)$ \\
\hline & Narrow: broad with additional criteria & 92 & 30.9 & $-35.5(-50.6$ to -23.4$)$ \\
\hline $\begin{array}{l}\text { Colonoscopy; } \\
\text { age<50years }(n=4017)\end{array}$ & Constipation & 133 & 3.31 & $-23.4(-38.1$ to -11.0$)$ \\
\hline \multirow[t]{2}{*}{ Spinal fusion $(n=544)$} & Broad: low back pain or spinal stenosis & 124 & 22.8 & $-6.2(-28.9$ to 11.2$)$ \\
\hline & Narrow: only low back pain & 8 & 1.5 & $-42.3(-109.0$ to -13.7$)$ \\
\hline \multirow{2}{*}{$\begin{array}{l}\text { Percutaneous coronary } \\
\text { interventions }(n=881)\end{array}$} & Broad: stable coronary disease & 112 & 12.7 & $51.1(7.8$ to 79.9$)$ \\
\hline & Narrow: broad with additional criteria & 110 & 12.5 & 54.2 (14.9 to 83.8$)$ \\
\hline $\begin{array}{l}\text { Adenoidectomy during } \\
\text { tube insertion procedure } \\
(\mathrm{n}=303)\end{array}$ & $\begin{array}{l}\text { Tube insertion procedure for otitis media } \\
\text { with effusion; age } \leq 12 \text { years }\end{array}$ & 86 & 28.4 & $4.5(-26.1$ to 29.3$)$ \\
\hline $\begin{array}{l}\text { Epidural steroid injections } \\
(\mathrm{n}=83)\end{array}$ & Low back pain & 27 & 32.5 & $81.9(-55.6$ to 149.0$)$ \\
\hline \multirow{2}{*}{$\begin{array}{l}\text { Inferior vena cava filter } \\
(\mathrm{n}=26)\end{array}$} & Broad: all patients & 26 & 100 & $52.2(-42.4$ to 104.0$)$ \\
\hline & Narrow: broad with additional criteria & 11 & 42.3 & $27.4(-57.7$ to 86.8$)$ \\
\hline \multirow{2}{*}{$\begin{array}{l}\text { Carotid endarterectomy } \\
(\mathrm{n}=59)\end{array}$} & Broad: asymptomatic, high-risk patients & 21 & 35.6 & $-32.1(-71.2$ to -7.6$)$ \\
\hline & Narrow: additional criteria & 15 & 25.4 & $-23(-78.1$ to 9.6$)$ \\
\hline \multirow{2}{*}{$\begin{array}{l}\text { Laparoscopic uterine } \\
\text { nerve ablation }(n=18)\end{array}$} & Broad: all patients & 18 & 100 & $52.2(-42.4$ to 104.0$)$ \\
\hline & Narrow: chronic pain & 5 & 27.8 & $27.4(-57.7$ to 86.8$)$ \\
\hline \multirow{2}{*}{$\begin{array}{l}\text { Endovascular repair } \\
\text { of abdominal aortic } \\
\text { aneurysm }(n=28)\end{array}$} & Broad: asymptomatic, high-risk patients & 13 & 46.4 & $-43.4(-75.5$ to -22.2$)$ \\
\hline & Narrow: broad with additional criteria & 5 & 17.9 & $-60.8(-91.4$ to -43.8$)$ \\
\hline \multirow[t]{2}{*}{$\begin{array}{l}\text { Renal artery angioplasty or } \\
\text { stent }(n=12)\end{array}$} & $\begin{array}{l}\text { Broad: renovascular hypertension or } \\
\text { atherosclerosis }\end{array}$ & 12 & 100 & $14.2(-70.3$ to 68.1$)$ \\
\hline & Narrow: broad with additional criteria & 10 & 83.3 & $8.1(-79.8$ to 48.4$)$ \\
\hline $\begin{array}{l}\text { Retinal laser or } \\
\text { cryotherapy }(n=437)\end{array}$ & Lattice degeneration & 9 & 2.1 & $79.0(-54.5$ to 172.0$)$ \\
\hline $\begin{array}{l}\text { Nasolacrimal duct } \\
\text { procedure; age } \leq 1 \text { year } \\
(\mathrm{n}=11)\end{array}$ & Blocked nasolacrimal duct & 8 & 72.7 & $-58.4(-97.1$ to -39.0$)$ \\
\hline $\begin{array}{l}\text { Hyperbaric oxygen } \\
\text { therapy }(n=28)\end{array}$ & Multiple indications & $<5$ & - & \\
\hline $\begin{array}{l}\text { Gallbladder removal } \\
\text { during obesity surgery } \\
(\mathrm{n}=11)\end{array}$ & Obesity surgery, no gallbladder disease & $<5$ & - & \\
\hline $\begin{array}{l}\text { Open obesity surgery } \\
\text { (opposed to laparoscopic) } \\
(\mathrm{n}<5)\end{array}$ & Primary bariatric procedure & $<5$ & - & \\
\hline Vertebroplasty $(\mathrm{n}<5)$ & All patients & $<5$ & - & \\
\hline
\end{tabular}

Continued

\begin{tabular}{lll}
$\begin{array}{lll}\text { Patients with LV } \\
\text { procedure (n) }\end{array}$ & LV (\%) & $\begin{array}{l}\text { \% Change 2010-2014 } \\
\mathbf{( 9 5 \% ~ C l )}\end{array}$ \\
\hline 2956 & 81.7 & $-24.2(-27.5$ to -21.3$)$ \\
1607 & 44.4 & $-21.1(-25.8$ to -17.1$)$ \\
501 & 10.0 & $-17.1(-26.3$ to -9.3$)$
\end{tabular}

LV patient-indication

Broad: osteoarthritis or meniscal derangements

Narrow: broad with additional criteria

501

10.0

$-17.1(-26.3$ to -9.3$)$ 


\begin{tabular}{|c|c|c|c|c|}
\hline \multicolumn{4}{|l|}{2014} & \multirow[b]{2}{*}{$\begin{array}{l}\text { \% Change 2010-2014 } \\
(95 \% \mathrm{Cl})\end{array}$} \\
\hline $\begin{array}{l}\text { Patients with procedure } \\
\text { (n) }\end{array}$ & LV patient-indication & $\begin{array}{l}\text { Patients with LV } \\
\text { procedure (n) }\end{array}$ & LV (\%) & \\
\hline $\begin{array}{l}\text { Electroconvulsive therapy; } \\
\text { age } \leq 12 \text { years }(n=0)\end{array}$ & Depression & 0 & - & \\
\hline \multirow{2}{*}{$\begin{array}{l}\text { All patients in cohort } \\
(n=141244)\end{array}$} & All broad indications & 4695 & 3.3 & \\
\hline & All narrow indications & 3044 & 2.2 & \\
\hline
\end{tabular}

Complete low-value procedure definitions are provided in online supplementary table 1.

received a low-value procedure in 2014. This equates to just over $2 \%$ of the entire admitted cohort receiving at least one of the investigated low-value procedures. The 2014 Medicare contribution towards low-value admissions was between $\$ A 1.8$ and $\$ A 2.9$ million. If the full spectrum of hospital procedures provided to all insured patients could be measured, this estimate might be considerably higher. Additional expenditure (not counted in this analysis) may have been incurred in managing in-hospital complications or other downstream harms and interventions resulting from these low-value procedures.

\section{Comparison to international results}

The US $^{625}$ and Canadian ${ }^{24}$ studies which applied the same method for directly measuring low-value care did so in data sets containing both in-hospital and primary care information. Because Australian private health insurers are principally responsible for care provided only during a hospital admission, we investigated only in-hospital services. Thus, the absence of some population-based screening interventions, and likely differences in the patient populations and data sets, explain the comparatively low proportion of the patient population in this

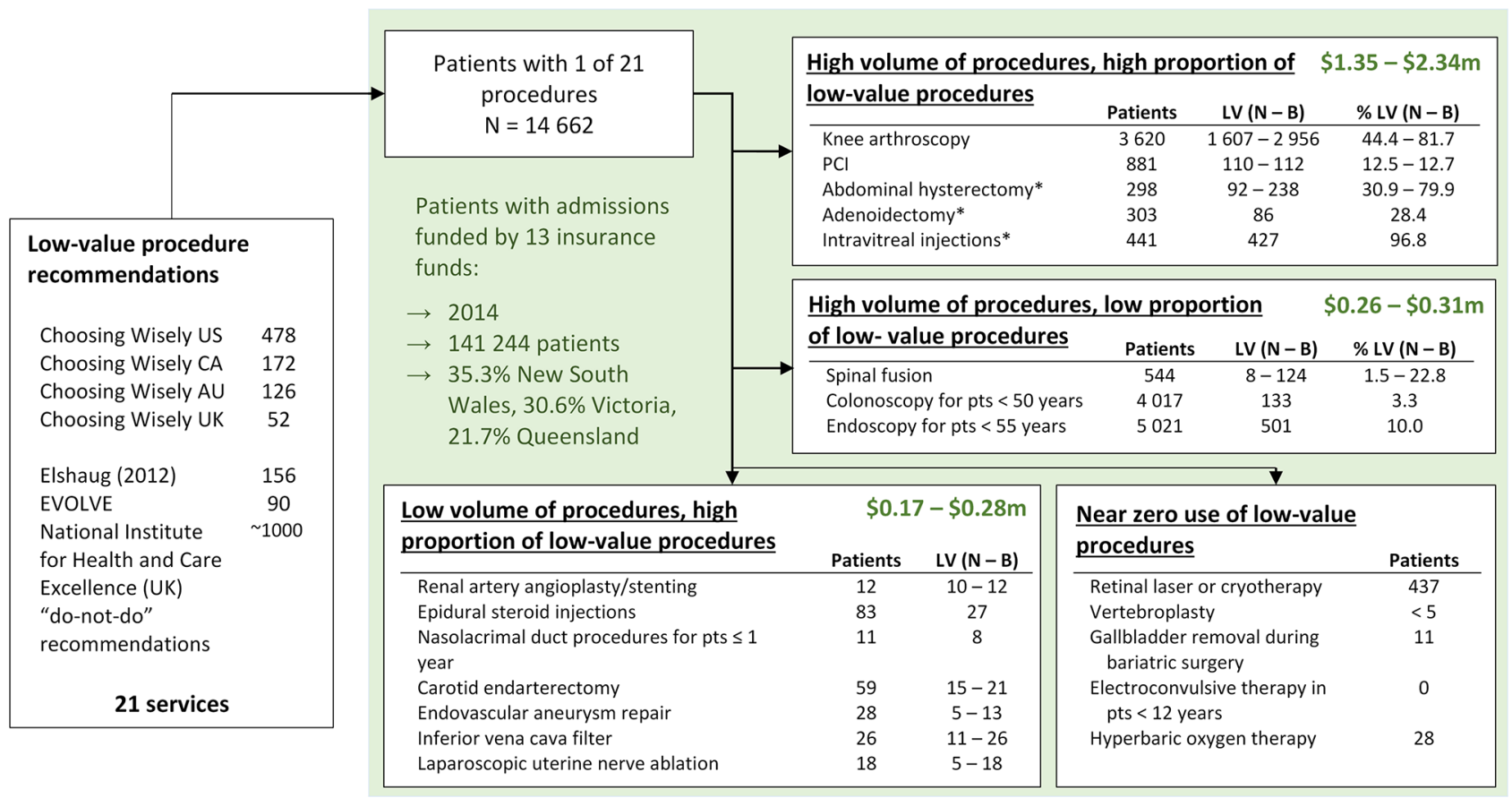

Figure 1 Indicators of 21 low-value procedures applied to a data set of health insurance claims. Broad (B) and narrow (N) indicators are used to identify low-value procedures based on differing recommendation/s. Results for procedures were categorised into four different groups depending on the numbers of patients with the procedure (high volume $>100$ procedures) and the proportion of low-value procedures (high proportion $>10 \%$ ). The Medicare (Australian government) contribution towards admissions with a low-value procedure in 2014 are shown for each category (*abdominal hysterectomy, adenoidectomy and inpatient intravitreal injections were not included in this total; all amounts are in Australian dollars). AU, Australia; CA, Canada; LV, low-value; PCI, percutaneous coronary interventions; pts, patients; UK, United Kingdom; US, United States; yr, year. 


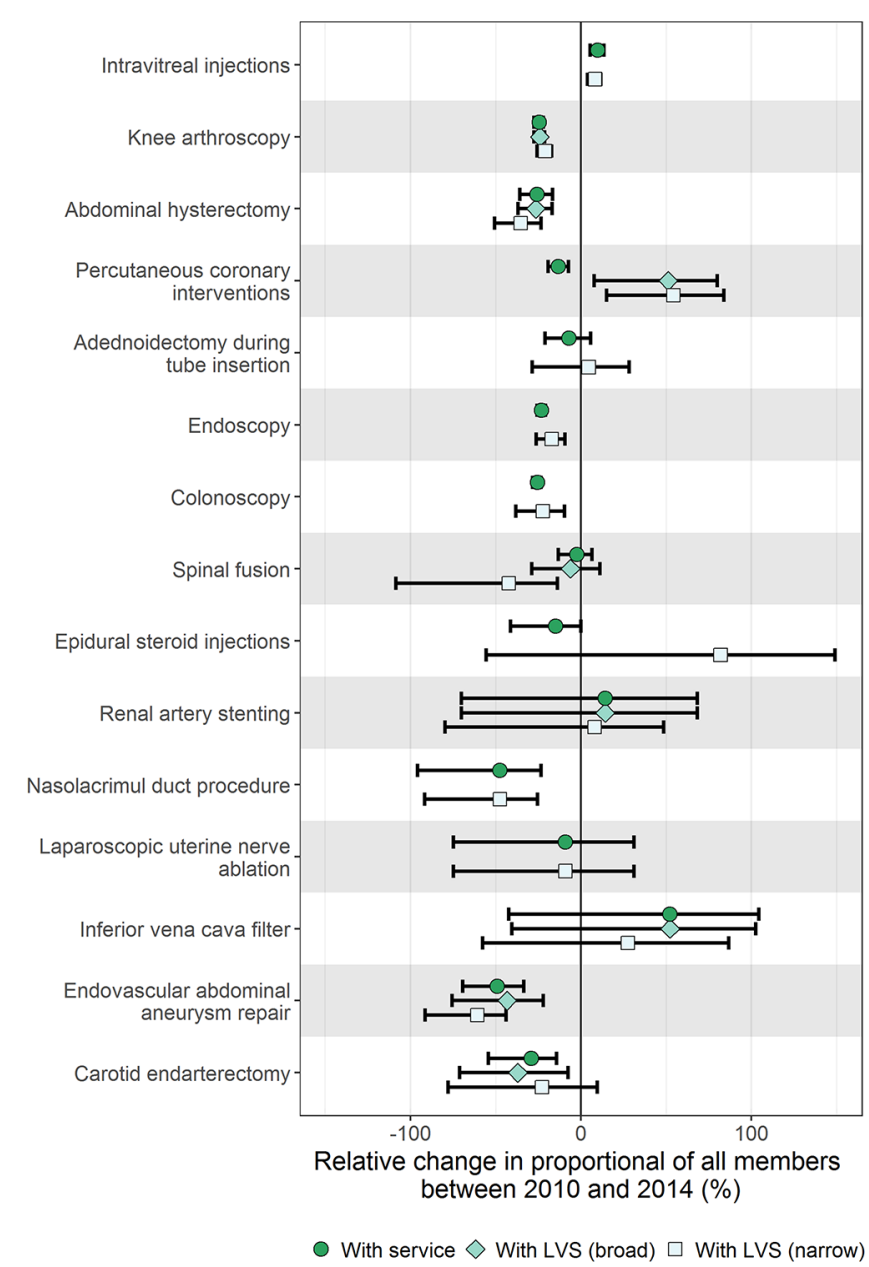

Figure 2 The relative change between 2010 and 2014 in the proportion of patients with the procedure (circle) and lowvalue procedure (broad: diamond, narrow: square) out of all patients with an admission; 95\% Cls are shown, based on bootstrap samples of 1000 replicates. LVS, low-value service.

study with a low-value procedure $(2 \%-3 \%$ compared with $25 \%-42 \%$ reported by Schwartz et al $)$. However, if we focus on the same six in-hospital procedures (knee arthroscopy, carotid endarterectomy, PCI, renal angioplasty, inferior vena cava filters, and vertebroplasty) as investigated in this study and the US studies, then the following proportion of beneficiaries received at least one of these six low-value procedures: $0.8 \%$ (narrow) to $1.8 \%$ (broad) of US Medicare beneficiaries ${ }^{6} ; 0.03 \%$ (narrow only) of a US commercially insured population ${ }^{25}$ and $1.2 \%$ (narrow) to $2.2 \%$ (broad) in our cohort of insured Australian patients with a hospital admission.

The most prevalent and costly low-value procedure we investigated was knee arthroscopy. Several randomised trials published between 2002 and 2013 demonstrated the unlikely clinical benefit of knee arthroscopy compared with conservative management for many patients, and guidelines globally reflected this (the National Institute for Health and Care Excellence do-not-do recommendation was released in 2008).$^{26}$ Our investigation showed that knee arthroscopy (all procedures and low-value procedures) decreased between 2010 and 2014. A recent study using Swiss health insurance claims also showed a decrease in surgical volume between 2012 and 2015, although the authors also found patients' type of insurance coverage was associated with undergoing a knee arthroscopy ${ }^{27}$ Comparisons between insurance types (particularly public vs privately insured patients) in Australia and low-value procedures have yet to be investigated.

\section{Limitations and implications}

Our study carries similar limitations as other reported projects using similar methods based on administrative data. ${ }^{6224}$ Like any investigation that directly measures low-value care, we were limited by the published recommendations and available definitions of low-value care and the clinical detail recorded within the data set. There are many CW recommendations, for example, that are not measurable within claims data, because the clinical detail required to distinguish potentially inappropriate from appropriate care is not available. ${ }^{1728}$

Another limitation is the uncertain representativeness of our sample for all privately insured Australians, as comparisons of patient characteristics between the memberships of different insurance funds were not possible.

Finally, the measures of low-value care we used in this study were derived from recommendations which were mostly issued after 2012 and have not been validated against other data sources, such as detailed clinical chart review, which is again a limitation common to all low-value care measurement studies using routinely collected administrative data. ${ }^{29}$ However, comparisons of indicators of inappropriate care based on administrative data (like we have done) versus chart reviews suggest the former yield conservative or indicative estimates of low-value care. These comparisons have only been done for a few services and administrative data sets, ${ }^{30-32}$ and further research and validation work on these indicators would be useful. ${ }^{29}$

Our study has several important implications for Australian and international policy makers. The decrease over time in the proportion of low-value care for many procedures suggests we have measured procedures amenable to reduction. This decrease may reflect changes in clinical practice due to increasing evidence-and awareness campaigns-about the low-value application of specific procedures. In contrast, the increase in low-value PCI admissions may reflect a perception that, in contrast to the measure of low-value care used in our study (derived from Schwartz et at and which relied on studies that only evaluated bare metal stents), use of new-generation drugeluting stents (DES) may improve outcomes in patients with stable coronary artery disease. ${ }^{33}$ However, a recent randomised trial which only used DES and compared PCI against a sham procedure control group re-affirmed no benefit from PCI in such patients. ${ }^{34}$

Other observations likely reflect alterations in clinical practice due to changes in government reimbursement eligibility and insurance fund coverage, such as 


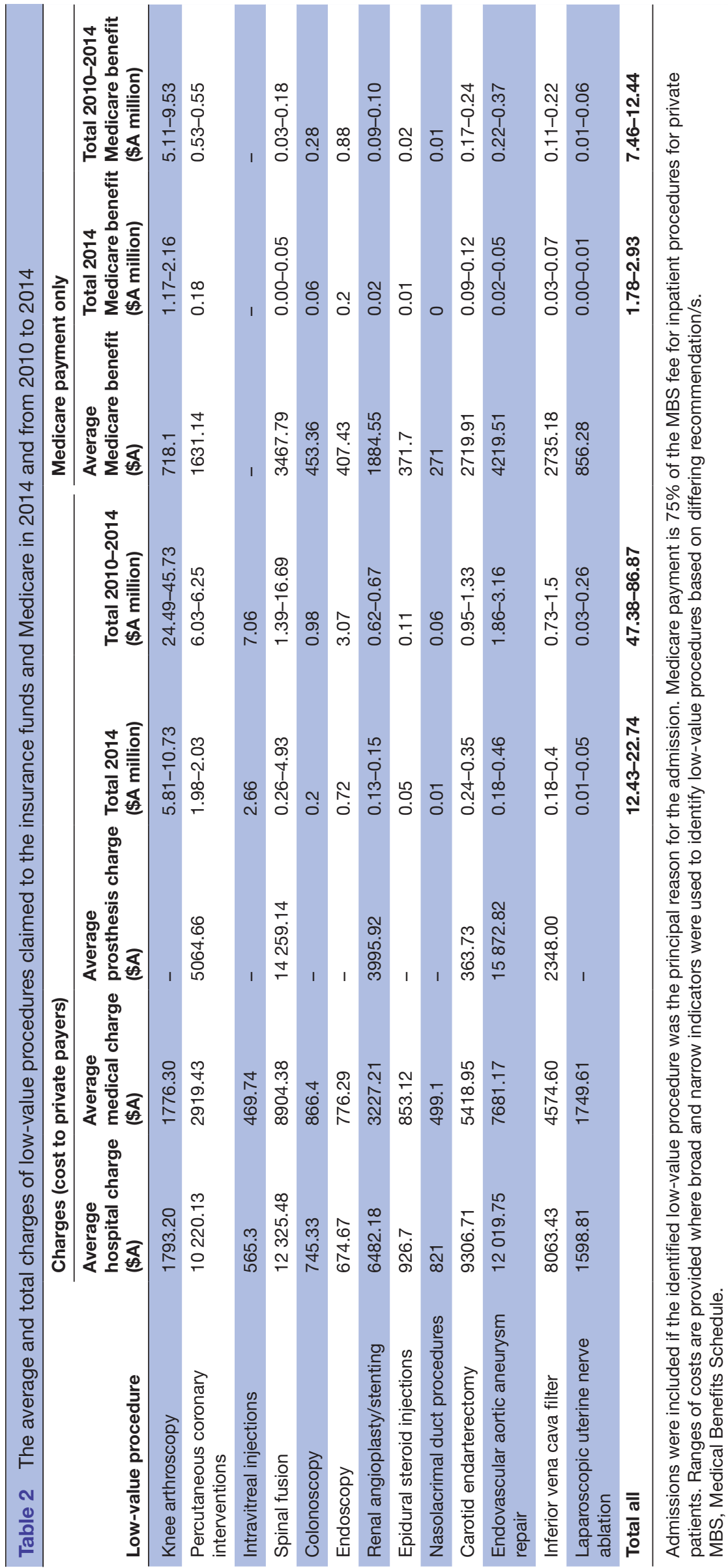

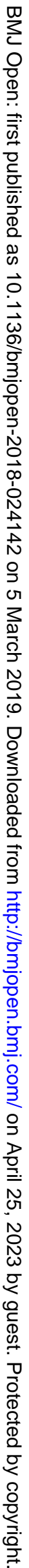


the removal of the vertebroplasty item from the MBS in 2011, and the introduction of a funding mechanism to allow intravitreal injections to be performed in inpatient settings in 2012. ${ }^{921}$ However, with respect to the latter, the CW Australia recommendation states that most intravitreal injections can be safely done in an outpatient setting, and:

this cost, initially borne by private health funds, clearly puts pressure on the sustainability of the private health system and contributes to the need to increase health insurance premiums and to reduce benefits for other procedures. ${ }^{2}$

In summary, the claims-based direct measures used in this study provide estimates of the extent of low-value care within a sizeable cohort of privately insured patients up to 2014 and can be used as baseline estimates in monitoring the impact of campaigns like CW in this and other patient cohorts. Measuring the scale of low-value care is a necessary prerequisite to developing policies which influence clinical decisions and reorientate the healthcare system towards high value care. The measures used in this study will benefit from further refinement as research and clinical experience, both in Australia and internationally, adds to the evidence base of what constitutes low-value care.

\section{Author affiliations}

${ }^{1}$ Menzies Centre for Health Policy, University of Sydney School of Public Health, Sydney, New South Wales, Australia

${ }^{2}$ Health Market Quality Program, Capital Markets CRC Ltd, Sydney, New South Wales, Australia

${ }^{3}$ Medicines Policy Research Unit, University of New South Wales, UNSW, New South Wales, Australia

${ }^{4}$ Department of Internal Medicine and Clinical Epidemiology, Princess Alexandra Hospital, Brisbane, Queensland, Australia

${ }^{5}$ Centre for Health Services Research, University of Queensland, Brisbane, Queensland, Australia

Acknowledgements The authors would also thank the 27 participants in a clinical workshop who reviewed the related methods and indicators used for NSW public hospital data; and Leanne Johnson and Sarah Barras from Australian Health Service Alliance for their advice and contribution to the cost estimates.

Contributors $\mathrm{KC}$ designed the study, conducted the data analysis and interpretation, and drafted the article. KC and TB-P developed the low-value procedure indicators with contributions from JB and IAS. S-AP and AGE had input into the study design and critical revision of the article. All authors had final approval of the article.

Funding This work was supported by the National Health and Medical Research Council (grant number 1109626); the Capital Markets Cooperative Research Centre under the Health Market Quality Program and their partners Hospital and Medical Benefits Systems and the New South Wales Ministry of Health; and the HCF Research Foundation. JB is funded by an NHMRC Postgraduate Scholarship (APPID: 1094304). AGE receives salary support as the HCF Research Foundation Professorial Fellow. KC and TB-P receive salary support via a doctoral scholarship from the Capital Markets Cooperative Research Centre-Health Market Quality Program. KC also receives support from an Australian Government Research Training Program Scholarship, and TB-P through a University Postgraduate Award from the University of Sydney.

Competing interests $\mathrm{KC}$ receives salary support via a doctoral scholarship from the Capital Markets Cooperative Research Centre-Health Market Quality Program, and consulting fees from Queensland Health Department. TB-P receives salary support via a doctoral scholarship from the Capital Markets Cooperative Research
Centre-Health Market Quality Program, and consulting fees from Queensland Health Department. AGE receives salary support as the HCF Research Foundation Professorial Research Fellow and is a Ministerial appointee to the Australian Medicare Benefits (MBS) Review Taskforce, receives consulting sitting fees from Cancer Australia, the Capital Markets Cooperative Research Centre-Health Quality Program, NPS MedicineWise (facilitator of Choosing Wisely Australia), The Royal Australasian College of Physicians (facilitator of the EVOLVE programme) and the Australian Commission on Safety and Quality in Health Care, and Queensland Health (state department of health), and is on the advisory board of the NSW Bureau of Health Information; S-AP is a member of the Drug Utilisation Sub-Committee of the Pharmaceutical Benefits Advisory Committee (PBAC) and receives consulting fees from NPS MedicineWise.

Patient consent for publication Not required.

Ethics approval The University of Sydney Human Research Ethics Committee (project ID 2015/662) approved the study.

Provenance and peer review Not commissioned; externally peer reviewed.

Data sharing statement The code used in this study is commercial-in-confidence. The data in this study are available from Hospital and Medical Benefits Systems, which were used under licence for the current study, and is not publicly available. Data are available from the authors on reasonable request and with permission from Hospital and Medical Benefits Systems.

Open access This is an open access article distributed in accordance with the Creative Commons Attribution Non Commercial (CC BY-NC 4.0) license, which permits others to distribute, remix, adapt, build upon this work non-commercially, and license their derivative works on different terms, provided the original work is properly cited, appropriate credit is given, any changes made indicated, and the use is non-commercial. See: http://creativecommons.org/licenses/by-nc/4.0/.

\section{REFERENCES}

1. Scott IA, Duckett SJ. In search of professional consensus in defining and reducing low-value care. Med J Aust 2015;203:179-81.

2. NPS Medicinewise. Choosing Wisely Australia. 2017. www. choosingwisely.org.au (cited 1 May 2017).

3. Brownlee S, Chalkidou K, Doust J, et al. Evidence for overuse of medical services around the world. Lancet 2017;390:156-68.

4. Private Health Insurance Administration Council (AU). Quarterly Statistics June 2014. Sydney, 2014.

5. Australian Institute of Health and Welfare. Admitted patient care 2014-15: Australian hospital statistics. Health services series no. 68. Canberra: AlHW. Cat. no. HSE 172.

6. Schwartz AL, Landon BE, Elshaug AG, et al. Measuring low-value care in medicare. JAMA Intern Med 2014;174:1067-76.

7. Srinivasan $U$, Arunasalam $B$. Leveraging big data analytics to reduce healthcare costs. IT Prof 2013;15:21-8.

8. National Centre for Classification in Health (AU). The Australian classification of health interventions. 7th edn. Lidcombe, NSW, 2010

9. Australian Government Department of Health and Ageing. Medicare Benefits Schedule Book. Canberra, 2012

10. National Centre for Classification in Health (AU). The International Statistical Classification of Diseases and Related Health Problems, Tenth Revision, Australian Modification. 7th edn. Lidcombe, NSW, 2010.

11. Royal Australian College of Physicians. EVOLVE 2016 www.evolve. edu.au/ (Cited 1 Apr 2017).

12. ABIM Foundation (US). Choosing Wisely. 2017. www.choosingwisely. org/ (Cited 1 May 2017).

13. Canadian Medical Association, University of Toronto. Choosing Wisely Canada. 2017. www.choosingwiselycanada.org/ (Cited 20 Jul 2017).

14. Choosing Wisely UK. 2017. www.choosingwisely.co.uk/ (Cited 1 May 2017).

15. National Institute for Health and Care Excellence (UK). NICE Guidance. 2017. https://www.nice.org.uk/guidance/published?type= cg (Cited 1 May 2017).

16. Elshaug AG, Watt AM, Mundy L, et al. Over 150 potentially lowvalue health care practices: an Australian study. Med J Aust 2012;197:556-60.

17. Chalmers K, Badgery-Parker T, Pearson SA, et al. Developing indicators for measuring low-value care: mapping Choosing Wisely recommendations to hospital data. BMC Res Notes 2018;11:163.

18. Bhatia RS, Levinson W, Shortt S, et al. Measuring the effect of choosing Wisely: an integrated framework to assess campaign impact on low-value care. BMJ Qual Saf 2015;24:523-31. 
19. Chalmers K, Pearson SA, Elshaug AG. Quantifying low-value care: a patient-centric versus service-centric lens. BMJ Qual Saf 2017;26:855-8

20. RStudio Team. RStudio: Integrated Development Environment for R. 2015. http://www.rstudio.com/ (Cited 1 Feb 2016).

21. Department of Health and Ageing. Classification of Medicare Benefits Schedule (MBS) item 42738 (intravitreal injection) in the Private Health Insurance (Benefit Requirements) Rules 2011. Canberra, 2012.

22. Colla $\mathrm{CH}$, Morden NE, Sequist TD, et al. Choosing wisely: prevalence and correlates of low-value health care services in the United States. J Gen Intern Med 2015;30:221-8.

23. Coronini-Cronberg S, Bixby H, Laverty AA, et al. English National Health Service's savings plan may have helped reduce the use of three 'low-value' procedures. Health Aff 2015;34:381-9.

24. McAlister FA, Lin M, Bakal J, et al. Frequency of low-value care in Alberta, Canada: a retrospective cohort study. BMJ Qual Saf 2018;27:340-6.

25. Reid RO, Rabideau B, Sood N. Low-value health care services in a commercially insured population. JAMA Intern Med 2016;176:1567-71.

26. Katz JN, Brownlee SA, Jones MH. The role of arthroscopy in the management of knee osteoarthritis. Best Pract Res Clin Rheumato 2014;28:143-56.
27. Muheim LLS, Senn O, Früh M, et al. Inappropriate use of arthroscopic meniscal surgery in degenerative knee disease: An observational study from Switzerland. Acta Orthop 2017;88:550-5.

28. Elshaug AG, McWilliams JM, Landon BE. The value of low-value lists. JAMA 2013;309:775-6.

29. de Vries EF, Struijs JN, Heijink R, et al. Are low-value care measures up to the task? A systematic review of the literature. BMC Health Serv Res 2016;16:405.

30. Avoundjian T, Gidwani R, Yao D, et al. Evaluating two measures of lumbar spine MRI overuse: administrative data versus chart review. $J$ Am Coll Radiol 2016;13:1057-66.

31. Maier B, Wagner K, Behrens S, et al. Comparing routine administrative data with registry data for assessing quality of hospita care in patients with myocardial infarction using deterministic record linkage. BMC Health Serv Res 2016;16:605.

32. Saini SD, Powell AA, Dominitz JA, et al. Developing and testing an electronic measure of screening colonoscopy overuse in a large integrated healthcare system. J Gen Intern Med 2016;31:53-60.

33. Windecker S, Stortecky S, Stefanini GG, et al. Revascularisation versus medical treatment in patients with stable coronary artery disease: network meta-analysis. BMJ 2014;348:g3859.

34. Al-Lamee R, Thompson D, Dehbi HM, et al. Percutaneous coronary intervention in stable angina (ORBITA): a double-blind, randomised controlled trial. Lancet 2018;391:31-40. 